\title{
EVALUASI SURVEILANS DEMAM BERDARAH DENGUE DI KABUPATEN BANGLI TAHUN 2017
}

\author{
Ni Wayan Sri Widyantari*, Made Pasek Kardiwinata, Ni Luh Putu Suariyani \\ Program StudiKesehatan Masyarakat Fakultas Kedokteran Universitas Udayana \\ *email : sriwidyantari@gmail.com
}

\begin{abstract}
ABSTRAK
Kejadian Demam Berdarah Dengue (DBD) di Kabupaten Bangli selama empat tahun beturut-turut mengalami peningkatan, dari tahun 2012 sebesar 22,7 per 100.000 penduduk menjadi 558,5 per 100.000 penduduk pada tahun 2016, dikarenakan Program Pengendalian DBD belum berajalan secara maksimal diantaranya belum terbentuknya kader jumantik dan sistem kewaspadaan dini rumah sakit yang belum berjalan. Penelitian ini bertujuan untuk evaluasi sistem surveilans DBD di Kabupaten Bangli berdasarkan penilaian input dan proses surveilans. Penelitian ini menggunakan rancangan evaluasi pada input dan proses dengan populasi puskesmas di Kecamatan Bangli, Tembuku, Susut, dan Dinkes Kabupaten Bangli. Sampel adalah seluruh populasi, dengan responden petugas surveilans. Data primer hasil wawancara dan observasi, sedangkan data sekunder melalui dokumentasi dan laporan surveilans. Data dianalisis secara deskriptif. Hasil dari komponen input sistem surveilans seperti tenaga, sarana dan dana belum sesuai standar. Komponen proses seperti data surveilans masih ada yang belum dianalisis. Penyebaran informasi melalui website dinas kesehatan juga belum dilakukan. Evaluasi surveilans berdasarkan atribut juga belum optimal. Melalui evaluasi sistem surveilans, diharapkan memberi masukan dalam perbaikan pengendalian DBD di Kabupaten Bangli.
\end{abstract}

Kata Kunci: Evaluasi, Surveilans, DBD

\begin{abstract}
Incidence of Dengue Hemorrhagic Fever (DHF) has increased for four consecutive year in Bangli region. The rate was 2012 of 22.7 per 100,000 population to 558.5 per 100,000 population in 2016. Jumantic cadres and hospitals alert system has not established. This study aim to evaluate the DHF surveillance system in Bangli District using input and surveillance processes. This study uses an evaluation design on inputs and processes to analise the surveillance system in puskesmas located in sub-district Bangli, Tembuku, Susut and Bangli District Health Offices. The sample of this study was the entire population, while the respondent was surveillance officers. Primary data sources was from interviews and observations, while secondary data collected through documentation and monitoring reports. Data were analyzed descriptively. Findings suggested that input components of surveillance system such as supervision, personnel, facilities and funds do not meet the standards, while surveillance data have not been analyzed. Dissemination of information through the health service website has not yet been carried out. Evaluation of surveillance based on attributes is also not optimal. Through an evaluation of the surveillance system, it is expected to provide input for the improvement of DHF supervision in Bangli Regency.
\end{abstract}

Keywords: Evaluation, Surveillance, Dengue Hemorrhagic Fever (DHF)

\section{PENDAHULUAN}

Penyakit Demam Berdarah Dengue (DBD) merupakan penyakit infeksi yang ditularkan melalui gigitan nyamuk Aedes aegypti, dimana hampir seluruh kota di Indonesia merupakan negara endemis DBD. Berdasarkan data Profil Kesehatan Indonesia 2015 angka insiden kasus DBD di Indonesia pada tahun 2015 dilaporkan 50,75 per 100.000 penduduk dengan angka kematian sebesar 0,83\%. Angka ini meningkat dari tahun 2014 yang angka insiden kasusnya sebesar 39,80 per 100.000 penduduk.

Kabupaten Bangli merupakan salah satu Kabupaten di Provinsi Bali dengan jumlah kasus DBD yang meningkat tiap tahunnya selama empat tahun berturut-turut, dari tahun 2012 dengan angka insiden sebesar 22,7 per 100.000 penduduk, meningkat di tahun 2013 menjadi 47,9 per 100.000 penduduk, tahun 2014 sebesar 117,9 per 100.000 
penduduk, tahun 2015 sebesar 155,9 per 100.000 penduduk dan terakhir tahun 2016 sebesar 558,5 per 100.000 penduduk.

Oleh sebab itu, pelaksanaan sistem surveilans yang sudah berjalan di Kabupaten Bangli perlu dilakukan evaluasi secara mendalam. Karena surveilans epidemilogi merupakan kegiatan yang sangat penting dalam mendukung pengendalian dan penanggulangan penyakit menular sebagai upaya deteksi dini terhadap kemungkinan terjadinya kejadian luar biasa (KLB), memperoleh informasi yang diperlukan bagi perencanaan dalam hal pencegahan, penanggulangan maupun pembrantasannya pada berbagai tingkat administrasi. Sehingga peningkatan angka insiden dan kematian karena kasus DBD pada tahun mendatang dapat dicegah (Depkes RI, 2004).

\section{METODE}

Rancangan penelitian ini adalah studi evaluasi yang merupakan bagian dari proses pembuat keputusan dengan membandingkan suatu kejadian, kegiatan dan produk dengan standar program yang telah ditetapkan. Populasi penelitian adalah seluruh puskesmas di Kabupaten Bangli dan Dinas Kesehatan Kabupaten Bangli. Populasi terjangkau adalah puskesmas di wilayah Kecamatan Bangli, Tembuku, Susut dan Dinas Kesehatan Kabupaten Bangli. Sampel adalah total populasi dengan responden petugas surveilans di masing-masing puskesmas di Kecamatan Bangli, Tembuku, Susut dan Staf Surveilans Dinas Kesehatan Kabupaten Bangli. Data yang digunakan dalam penelitian ini adalah data primer dan sekunder. Data primer diperoleh dengan wawancara dan observasi. Data sekunder diperoleh dari dokumentasi laporan program surveilans. Data dianalisis secara deskriptif.

\section{HASIL}

\section{Input}

\section{a. Tenaga}

Indikator tenaga surveilans puskesmas berdasarkan KMK No. 1116 Tahun 2003 melalui hasil wawancara terstruktur diperoleh hasil sebagai berikut :

\section{Tabel 1. Indikator Tenaga}

\begin{tabular}{lccc}
\hline Item & \multicolumn{2}{c}{ Standar Tenaga } & Total \\
\cline { 2 - 3 } & Sesuai & Tidak Sesuai & \\
\hline Jumlah petugas & $1(16,67 \%)$ & $5(83,33 \%)$ & $6(100 \%)$ \\
\hline Kualifikasi pendidikan & $0(0 \%)$ & $6(100 \%)$ & $6(100 \%)$ \\
\hline Tidak rangkap jabatan/ tugas & $2(33,33 \%)$ & $4(66,67 \%)$ & $6(100 \%)$ \\
\hline Pelatihan & $0(0 \%)$ & $6(100 \%)$ & $6(100 \%)$ \\
\hline
\end{tabular}

Untuk tenaga surveilans di Dinas Kesehatan Kabupaten Bangli dari segi jumlah tenaga dan kualifikasi pendidikan masih belum sesuai, petugas masih rangkap jabatan dan belum pernah mendapat pelatihan khusus tentang surveilans. 
Arc. Com. Health Juni 2018

ISSN: 2527-3620

\section{b. Sarana}

Indikator sarana pendukung kegiatan surveilans puskesmas berdasarkan
Vol. 5 No. $1: 33$ - 42

indikator KMK No. 1116 Tahun 2003 adalah sebagai berikut :

Tabel 2. Indikator Sarana

\begin{tabular}{lccc}
\hline Item & \multicolumn{2}{c}{ Standar Sarana Pendukungan } & \multirow{2}{*}{ Total } \\
\cline { 2 - 3 } & Sesuai & Tidak & \\
\hline $\begin{array}{l}\text { Komputer dan } \\
\text { perlengkapannya }\end{array}$ & $4(66,67 \%)$ & $2(33,3 \%)$ & $6(100 \%$ \\
\hline Komunikasi & $3(50 \%)$ & $3(50 \%)$ & $6(100 \%)$ \\
\hline Referensi surveilans & $0(0 \%)$ & $6(100 \%)$ & $6(100 \%)$ \\
\hline $\begin{array}{l}\text { Pedoman pelaksanaan } \\
\text { surveilans }\end{array}$ & $6(100 \%)$ & $0(0 \%)$ & $6(100 \%)$ \\
\hline $\begin{array}{l}\text { Formulir perekaman data } \\
\text { surveilans }\end{array}$ & $6(100 \%)$ & $0(0 \%)$ & $6(100 \%)$ \\
\hline Sarana transportasi & $0(0 \%)$ & $6(100 \%)$ & $6(100 \%)$ \\
\hline
\end{tabular}

Untuk sarana pendukung kegiatan surveilans di Dinas Kesehatan Kabupten Bangli hanya satu indikator yang belum sesuai yaitu belum tersedianya referensi surveilans DBD.

Tabel 3. Pembiayaan Kegiatan Surveilans

\begin{tabular}{lccc}
\hline Item & Sesuai & Tidak & Total \\
\hline $\begin{array}{l}\text { Dana untuk kegiatan } \\
\text { surveilans DBD }\end{array}$ & $4(66,67 \%)$ & $2(33,33 \%)$ & $6(100 \%)$ \\
\hline Kecukupan dana & $4(66,67 \%)$ & $2(33,3 \%)$ & $6(100 \%)$ \\
\hline
\end{tabular}

Di Dinas Kesehatan tersedia dana tapi tidak cukup untuk melaksanakan kegiatan surveilans secara optimal.

\section{d. Sumber Data}

Dari hasil wawancara dengan petugas surveilans di puskesmas, sumber data laporan surveilans adalah sebagai berikut:

Tabel 4. Sumber Data Laporan Surveilans

\begin{tabular}{lccc}
\hline Item & \multicolumn{2}{c}{ Laporan } & Total \\
\cline { 2 - 3 } & Ada & Tidak & \\
\hline Puskesmas Pembantu & $6(100 \%)$ & $0(0 \%)$ & $6(100 \%)$ \\
\hline
\end{tabular}




\begin{tabular}{lccc}
\hline Rumah Sakit & $3(50 \%)$ & $3(50 \%)$ & $6(100 \%)$ \\
\hline Klinik/ dokter praktek & $0(0 \%)$ & $6(100 \%)$ & $6(100 \%)$ \\
\hline Kunjungan puskesmas & $6(100 \%)$ & $0(0 \%)$ & $6(100 \%)$ \\
\hline Survei langsung & $1(16,67 \%)$ & $5(83,33 \%)$ & $6(100 \%)$ \\
\hline Masyarakat & 1 & 5 & $6(100 \%)$ \\
\hline
\end{tabular}

Laporan surveilans Dinas Kesehatan bersumber hanya dari laporan surveilans puskesmas.

Tabel 5. Frekuensi Pengumpulan Data

\section{e. Frekuensi Pengumpulan Data}

Dari hasil wawancara dengan petugas surveilans dipuskesmas, frekuensi pengumpulan data dari puskesmas ke Dinas Kesehatan Kabupaten adalah sebagai berikut:

\begin{tabular}{lccc}
\hline Item & \multicolumn{2}{c}{ Frekuensi Pelaporan } & \multirow{2}{*}{ Total } \\
\cline { 2 - 3 } & Melapor & Tidak & \\
\hline Laporan mingguan & $6(100 \%)$ & $0(0 \%)$ & $6(100 \%)$ \\
\hline $\begin{array}{l}\text { Surveilans Terpadu } \\
\text { Penyakit (W2) }\end{array}$ & $6(100 \%)$ & $0(0 \%)$ & $6(100 \%)$ \\
\hline Laporan KLB (W1) & & & \\
\hline
\end{tabular}

\section{Proses}

\section{a. Pengumpulan Data}

Pengumpulan data dilakukan oleh bidan pustu ke petugas puskesmas melalui sms paling lambat Hari Senin, kemudian petugas surveilans puskesmas mengirim laporan ke Dinas Kesehatan Kabupaten Bangli selambat-lambatnya Hari Selasa melaui sms sesuai format. Laporan sms dari petugas surveilans akan langsung masuk ke software surveilans sehingga mampu diakses sampai ke tingkat pusat.

Untuk laporan bulanan sesuai dengan format dikirim oleh petugas surveilans puskesmas ke kabupaten paling lambat tanggal 5 pada bulan berikutnya. Petugas
Dinas Kesehatan Kabupaten/ Kota mengirim laporan surveilans ke Dinas Kesehatan Propinsi selambat-lambatnya tanggal 10 pada bulan berikutnya.

\section{b. Kompilasi Data}

Semua petugas surveilans baik di Dinas Kesehatan maupun puskesmas berdasarkan hasil wawancara dan observasi, sudah melakukan pengecekan data sebelum direkap dan dianalisis, serta melakukan kompilasi data berdasarkan tempat, orang dan waktu.

\section{c. Interpretasi dan Analisis Data}

Hasil wawancara dengan petugas surveilans, data laporan surveilans diolah dan dianalisis seperti tabel berikut : 
Arc. Com. Health • Juni 2018

ISSN: 2527-3620

Vol. 5 No. 1 : 33 - 42

Tabel 6. Interpretasi dan Analisis Data

\begin{tabular}{lccc}
\hline Item & Ya & Tidak & Total \\
\hline $\begin{array}{l}\text { Data yang dimiliki selalu } \\
\text { diolah }\end{array}$ & $5(83,33 \%)$ & $1(16,67 \%)$ & $6(100 \%)$ \\
\hline $\begin{array}{l}\text { Data yang diolah disajikan } \\
\text { dalam bentuk tabel/grafik/ }\end{array}$ & 3 & 3 & $6(100 \%)$ \\
peta & $(50 \%)$ & $(50 \%)$ & \\
\hline Data yang disajikan dianalisis & $1(16,67 \%)$ & $5(83,33 \%)$ & $6(100 \%)$ \\
\hline $\begin{array}{l}\text { Data diolah dan dianalisis } \\
\text { menurut wilayah }\end{array}$ & $1(16,67 \%)$ & $5(83,33 \%)$ & $6(100 \%)$ \\
\hline
\end{tabular}

Interpretasi dan analisis data surveilans DBD di Dinas kesehatan dilakukan mulai dari mengolah data yang disajikan dalam bentuk tabel, dilakukan analisis perbandingan, dan data dianalisis menurut wilayah. Analisis hanya dilakukan satu tahun sekali yaitu dalam rangka penyusunan profil kesehatan.

\section{d. Penyebaran Informasi}

Berdasarkan hasil wawancara ada satu puskesmas atau sebesar $16,67 \%$ tidak melakukan penyebarluasan informasi epidemiologi, sebesar 33,33\% puskesmas tidak menyebarluaskan informasi kepada lintas program dan lintas sektor, dan sebesar $50 \%$ puskesmas tidak rutin menyebarluaskan informasi 1 bulan sekali.

Data surveilans yang ada di Dinas Kesehatan Kabupaten Bangli dilakukan penyebarluasan informasi epidemiologi melalui lintas program dan lintas sektor, data yang disebarkan berupa laporan yang dilaksanakan 1 bulan sekali dan ketika terdapat kejadian berpotensi wabah, dan petugas mengatakan tidak ada hambatan dalam menyebarluaskan informasi.

\section{DISKUSI}

\section{Input}

a. Tenaga

Berdasarkan standar KMK RI No. 1116/SK/VIII/2003 tentang Pedoman Penyelenggaraan Sistem Surveilans Epidemiologi Kesehatan, jumlah tenaga surveilans yang ada di puskesmas sebesar $83,33 \%$ belum mencukupi dan sebesar $66,67 \%$ masih rangkap tugas serta kualifikasi pendidikan semua petugas belum sesuai dengan standar indikator. Tenaga yang kurang dan masih banyak tugas rangkap sangat berpengaruh terhadap kinerja petugas, yang menyebabkan kegiatan surveilans DBD tidak bisa terfokus. Sementara kualifikasi pendidikan yang tidak sesuai standar menyebabkan masih kurangnya tingkat pengetahuan petugas tentang pelaksanaan surveilans DBD. Untuk meningkatkan pengetahuan petugas, perlu diberikan pelatihan khusus tentang surveilans sehingga pelaksanaan surveilans mampu berjalan lebih optimal. Hal yang sama disampaikan oleh Agung (2013) bahwa pelatihan yang dilakukan terhadap petugas surveilans mampu 
meningkatkan kemapuan petugas dalam melakukan pengolahan data, analisis data dan penyebaran informasi

\section{b. Sarana}

Sarana merupakan sumber daya yang dapat dipergunakan untuk membantu menyelesaikan tujuan dengan baik. Tanpa sarana tugas dan tujuan spesifik tidak dapat diselesaikan sebagaimana seharusnya (Wibowo, 2007). Sedangkan menurut Depkes RI (2003) sarana dan prasarana merupakan salah satu faktor pendukung terselenggaranya kegiatan surveilans, sehingga sarana dan prasarana harus tersedia, dapat dimanfaatkan dengan baik dan mudah dioperasikan.

Sarana yang ada masih kurang dan belum memenuhi standar indikator yang telah ditetapkan dalam KMK No. 1116 tentang Pedoman Penyelenggaraan Sistem Surveilans Epidemiologi Kesehatan. Ketidaktersediaan sarana pendukung surveilans akan menyebabkan terhambatnya kegiatan surveilans, banyak kegiatan spesifik yang tidak terlaksana yang berakibat terhadap ketidakmampuan dan keterlambatan dalam penanggulangan kasus DBD. Hal serupa disampaikan oleh Rahayu (2012) bahwa sarana pendukung yang memadai sangat diperlukan dalam mencapai tujuan suatu kebijakan, karena tanpa sarana dan prasarana kegiatan spesifik tidak bisa dilaksanakan semestinya bahkan dapat menimbulkan hambatan.

\section{c. Dana}

Dana yang tersedia dalam kegiatan surveilans DBD di Kabupaten Bangli masih kurang, dana lebih banyak dialokasikan untuk pembangunan infrastruktur dan pengadaan alat teknis. Kondisi ini menyebabkan kegiatan surveilans tidak dapat berjalan secara optimal yaitu kegiatan surveilans sesuai dengan pedoman tidak dapat dijalankan. Kegiatan pelacakan kasus ke lapangan masih belum optimal dan kegiatan PSN belum menyeluruh karena PSN dilakukan oleh petugas kesehatan tanpa melibatkan kader. Ini dikarenakan belum terbentuknya kader jumantik yang disebabkan terbatasnya anggaran. Padahal tersedianya dana yang memadai sangatlah penting dalam mendukung suksesnya pembangunan kesehatan (Sukarna, 2006). Hal yang sama disampaikan oleh Rahayu (2012) tidak tersedianya dana yang cukup dapat menyebabkan tidak maksimalnya pelaksanaan kegiatan.

\section{d. Sumber Data}

Sumber data yang paling berperan dalam kegiatan surveilans DBD di puskesmas adalah data dari puskesmas pembantu dan surveilans langsung ke desa. Surveilans langsung tidak dapat dilakukan ke semua desa karena masih kurangnya tenaga dan sarana pendukung. Untuk Dinas Kesehatan Kabupaten Bangli, sumber data yang penting adalah Puskesmas dan jaringannya serta rumah sakit. Namun surveilans rumah sakit atau Kewaspadaan Dini Rumah Sakit (KDRS) di Kabupaten Bangli belum berjalan baik rumah sakit pemerintah maupun swasta, sehingga selama ini laporan surveilans DBD hanya berasal dari puskesmas. Untuk data DBD dari rumah sakit hanya berupa laporan bulanan. Seharusnya 
rumah sakit kabupaten/ kota berperan dalam melaksanakan surveilans kasus DBD di rumah sakit, mengidentifikasi rujukan kasus DBD sebagai sumber data surveilans DBD ke Dinas Kesehatan Kabupaten/ Kota dan melakukan kajian epidemiologi kasus DBD dan masalah DBD lainnya di rumah sakit (Kemenkes, 2011). Hal serupa disampaikan oleh Natalia (2011) bahwa laporan adanya kasus DBD di rumah sakit harus segera dilaporkan ke Dinas Kesehatan Kabupaten/ Kota agar dapat dilakukan tindakan pencegahan dan penanggulangan dengan segera, yaitu dilaporakan selama 1x24 jam setelah penegakan diagnosis.

\section{e. Frekuensi Pengumpulan Data}

Frekuensi pengumpulan data mingguan dan bulanan dari puskesmas ke Dinas Kesehatan sudah sesuai dengan pedoman sistem kewaspadaan dini dan respon, walaupun masih ada data yang tidak terlaporkan dari sumber data seperti dokter praktek swasta, klinik dan rumah sakit.

\section{Proses}

\section{a. Pengumpulan Data}

Data yang diterima dan diolah oleh sistem surveilans masih belum lengkap seperti data surveilans rumah sakit dan dokter praktek swasta, klinik dan rumah sakit. Data yang terkumpul di Dinas Kesehatan hanya laporan surveilans dari puskesmas dan masih ada dua puskesmas (33,3\%) yang tidak sesuai dengan batas waktu yang disepakati dalam melaporakan data surveilans. Keterlambatan pengiriman laporan menyebabkan terlambatnya kegiatan surveilans dari pengumpulan data, kompilasi, analisis dan penyebaran informasi.

\section{b. Kompilasi Data}

Data surveilans yang terkumpul di Kabupaten Bangli baik di Dinas Kesehatan maupun di Puskesmas dikompilasi berdasarkan karakteristik tempat, orang dan waktu. Namun masih ada beberapa puskesmas yang penyimpanan data surveilans hanya menggunakan form, hal ini dikarenakan tidak tersedianya sarana komputer khusus untuk kegiatan surveilans dan komputer yang tersedia di puskesmas masih sangat kurang. Stabilitas data yang rendah menyebabkan kesulitan dalam memantau trend kasus DBD dari waktu ke waktu, pemantauan kasus tidak maksimal, dan rendahnya kualitas data yang tersedia. Tentu saja keadaan ini berpengaruh pada

\section{c. Analisis dan Interpretasi Data}

Data surveilans DBD Dinas Kesehatan Kabupaten Bangli dilakukan analisis berupa analisis perbandingan, analisis hanya dilakukan 1 tahun sekali yaitu pada saat penyusunan profil kesehatan kabupaten, sedangkan untuk data surveilans di puskesmas masih ada petugas yang tidak melakukan analisis dikarenakan beban kerja yang terlalu tinggi. Data yang tidak dianalisis akan menyebabkan terhambatnya penyebaran informasi. Padahal Data yang sudah diolah menjadi gambar lebih mudah dipahami dan dibaca oleh semua pihak termasuk pemegang kebijakan sehingga keputusan untuk melakukan penanggulangan dapat dilaksanakan 
cepat dan tepat (Agung, 2013). Kondisi ini menyebabkan data yang ada tidak mampu menggambarkan masalah kesehatan yang sebenarnya sehingga pengendalian penyakit DBD tidak optimal dan terlambatnya penanggulangan kasus.

\section{d. Penyebaran Informasi}

Penyebaran informasi bisa dilakukan dalam bentuk buletin, surat edaran, laporan berkala, forum pertemuan dan publikasi ilmiah (Depkes, 2004). Upaya untuk lebih memudahkan diseminasi bisa dilakukan dengan memanfaatkan sarana teknologi informasi yang dapat denagn mudah diakses.

Penyebaran informasi surveilans DBD di Kabupaten Bangli dalam hanya dalam bentuk laporan dan lokakarya. Penyebaran informasi lewat media elektronik seperti website Dinas Kesehatan Kabupaten Bangli belum pernah dilakukan, ini dikarenakan beban kerja petugas yang cukup tinggi. Frekuensi waktu penyebaran ada yang satu bulan dan ada yang tiga bulan. Terlambatnya penyebaran informasi menyebabkan terlambatnya pengendalian penanggulangan kasus, sehingga penyebaran dan peningkatan kasus tidak mampu dihindari.

\section{SIMPULAN}

Evaluasi sistem surveilans DBD di Kabupaten Bangli pada tahun 2017 berdasarkan komponen input : jumlah tenaga surveilans masih kurang, kualifikasi pendidikan petugas belum sesuai, masih rangkap jabatan, dan tidak pernah mengikuti pelatihan terkait surveilans DBD. Dari segi pendanaan belum mencukupi, sebagian tidak menganggarkan $(33,33 \%)$, dan sarana pendukung yang terbatas. Sedangkan frekuensi pengumpulan data dari puskesmas ke Dinas Kesehatan sudah sesuai dengan jadwal yang ditetapkan. Evaluasi surveilans DBD berdasarkan komponen proses adalah dari pengumpulan data masih belum lengkap karena masih ada sumber data yang tidak melapor seperti rumah sakit dan klinik.

\section{DAFTAR PUSTAKA}

Agung, Suarjana, Larasati. (2013). Efektifitas Pelatihan Terhadap Kinerja Petugas Surveilans di Kabupaten Badung. Jurnal Skala Husada 10 (1): 89-92.

Barr C., Hoefer D., Cerry B., Noyes KA. (2011). A Process Evaluation of an Active Surveillance System for Hospitalized 2009-2010 H1N1 Influenza Cases. http://www.ncbi.nlm.nih.gov/pub med/21135655 (sitasi 15 Juni 2017)

CDC. (2001). Updated Guidelines for Evaluating Public Health Surveillance Systems. https://www.cdc.gov/mmwr/previ ew/mmwrhtml/rr5013a1.htm.

(sitasi 16 Pebruari 2017).

Depkes RI, (2003). Kepmenkes RI Nomor 1116/Menkes/SK/VIII/2003 tentang Pedoman Penyelenggaraan Sistem Surveilans Epidemiologi Kesehatan.

Depkes RI. (2004). Sistem Kesehatan Nasional. 
Dikes Prop. Bali, (2016). Profil Kesehatan

Propinsi Bali Tahun 2015.

Dikes Kab. Bangli, (2016). Profil Kesehatan Kabupaten Bangli Tahun 2015.

Dikes Kab. Bangli, (2017). Profil Kesehatan Kabupaten Bangli Tahun 2016.

Ditjen P2Pl. (2012). Penyelidikan dan Penanggulangan Kejadian Luar Biasa Penyakit Menular dan Keracunan Pangan. Kemenkes RI: 46-47.

Ditjen P2Pl. (2011). Modul Pengendalian Demam Berdarah Dengue. Kemenkes RI: 17-33.

Ditjen P2PL. (2007). Penyelidikan dan Penanggulangan Kejadian Luar Biasa (Pedoman Epidemiologi Penyakit). Depkes RI: 30-31.

Ditjen P2PL. (2007). Buku Pedoman petunjuk Teknis Pembrantasan Penyakit Demam Berdarah Dengue. Depkes RI.

Gubler, Duane J. (1998). Dengue and Dengue Hemorrhagic Fever. Clinical Microbiology Reviews: 484-485.

Guerdan, Bruce R. (2010). Dengue Fever/Dengue Hemorrhagic Fever. American Journal of Clinical Medicine: 51-52.

Hadari, Nawawi. (2005). Penelitian Terapan.Yogyakarta:Gajah Mada University Press.

Handayani, Mulasari, Nurdianis. (2008). Evaluasi Program Pemberian Makanan Tambahan Anak Balita. Fakultas Kesehatan Masyarakat
Vol. 5 No. $1: 33$ - 42

Universitas Ahmad Dahlan, Yogyakarta: 22-25.

Hidajah, A. C., Hargono, Yudhastuti. (2005). Evaluasi Pelaksanaan Surveilans Epidemiologi dan Upaya Pengendalian Penyakit Demam Berdarh Dengue di Kota Surabaya. Penelitian Universitas Airlangga, Surabaya.

John W, Creswell. (2013). Reseach Design, Qualitative, Quantitative and Approaches. Sage Publication, London.

Kartono. (2006). Profesi dan Praktek Keperawatan Profesional. Jakarta: ECG

Kemenkes RI. (2016). Profil Kesehatan Indonesia Tahun 2015.

Kemenkes RI. (2013). Pedoman Sistem Kewaspadaan Dini dan Respon.

Mahfudhoh, Binti. (2015). Komponen sistem Surveilans Demam Berdarah Dengue (DBD) di Dinas Kesehatan kota Kediri. Fakultas Kesehatan Masyarakat Universitas Airlangga, Surabaya: 96.

Malikhatin, Siti. Hendrati, Lucia. (2014). Kualitas Sistem Surveilans Pes Kabupaten Pasuruan Tahun 2014 Berdasarkan Peninlaian Atribut Sistem surveilans. Universitas Airlangga, Surabaya: 70-71.

Nasir, Abd. (2011). Buku Ajar Metodelogi Penelitian Kesehatan. Nuha Medika, Yogyakarta: 132.

Natalia, Aryanti. (2012). Gambaran Pelaksanaan Surveilans Epidemiologi Penyakit Demam 
Berdarah Dengue Ditinjau dari Aspek Petugas di Tingkat Puskesmas Kota Semarang Tahun 2011. Jurnal Kesehatan Masyarakat $1(2): 262-271$.

Notoatmodjo, S. (2007). Kesehatan Masyarakat Ilmu dan Seni. Rineka Cipta, Jakarta: 103.

PAEI. (2016). Pelatihan Surveilans Epidemiologi Rumah Sakit.

Rahayu, Tri. (2012). Evaluasi Pelaksanaan Program Pencegahan dan Penanggulangan Penyakit Demam Berdarah Dengue di Wilayah Kerja Puskesmas Ketapang II. Jurnal Kesehatan Masyarakat 1 (2), UNDIP: 479-492

Ranzinger, Silvia Runge. (2008). What Does Dengue Disease Surveillance Contribute to Predicting and Detecting Outbreaks and Dercribing Trends?Tropical Medicine and International Health: 1023.

Simamora, Henry. (2006). Manajemen Sumber Daya Manusia, Edisi 2. STIE YKPN.,Yogyakarta.

Sitepu, Frans.Y., Suprayogi, Antonius. Pramono, Dibyo. ( 2012). Evaluasi dan Implementasi Sistem Surveilans Demam Berdarah Dengue (DBD) di Kota Singkawang, Kalimantan Barat. Artikel Vol. 8., Universitas Gajah Mada.

Sitepu, Frans Y. (2013). Evaluasi Program Pengendalian dan Pencegahan Demam Berdarah Dengue (DBD) di Sumatera Utara Tahun 20102011. Dinas Kesehatan Propinsi Sumatera Utara: 3.

Sukarna, Laode Ahmad. Budiningsih, Nanis. Riyarto, Sigit. (2006). Analisis Kesiapan Dinas Kesehatan dalam Mengalokasikan Anggaran Kesehatan pada Era Desentralisasi. Jurnal Manajemen Pelayanan Kesehatan. 9(1): 10-18

WHO. (2012). Global Strategy for Dengue Prevention and Control.

WHO. (2009). Treatment, Prevention and control.

Wibowo. (2007). Manajemen Kinerja. PT. Raja Grafindo Parsada, Jakarta.

Zumaroh. (2015). Evaluasi Pelaksanaan Surveilans Kasus Demam Berdarah Dengue di Puskesmas Putat Jaya Berdasarkan Atribut Surveilans. Jurnal Berkala Epidemiologi, 88-92. 